Article

\title{
Analysis of a Rural Northwestern China Household Energy Use Survey Focusing on Parabolic Solar Cooker Use for Water Purification
}

\author{
Abigail R. Clarke-Sather 1,2,*, Curt J. Davis ${ }^{3}$, Jiansheng $Q \mathbf{u}^{2}$ \\ 1 Department of Mechanical and Industrial Engineering, University of \\ Minnesota Duluth, Voss Kovach Hall 105, 1305 Ordean Court, Duluth, MN \\ 55812, USA \\ 2 Chinese Academy of Sciences (CAS) Information Center for Global Change \\ Studies, Lanzhou Information Center, Chinese Academy of Sciences, 8 Middle \\ Tianshui Road, Lanzhou 730000, China \\ 3 Energy and Environmental Policy, University of Delaware, Graham Hall, \\ Newark, DE 19716, USA \\ * Correspondence: Abigail R. Clarke-Sather, Email: abbie@d.umn.edu; \\ Tel.: +1-218-726-8424.
}

\begin{abstract}
Background: Billions of people lack clean drinking water access. Many of the same people lack clean cooking systems, which can purify water by boiling, a viable form of decentralized water treatment. The combined health consequences of water scarcity, waterborne disease and smokerelated illnesses from burning solid fuels indoors can be addressed via clean cooking technologies such as parabolic solar cookers (PSCs).
\end{abstract}

Methods: A household energy survey in rural Anding district, Gansu province, China found the majority of households utilized PSCs solely for water purification through boiling. Households were aggregated into four categories of PSC use: All Year, Summer Only, No PSC Use (own but do not use), or No PSC (do not own). Statistical comparison of differences between household groups' means was carried out using Excel, JMP, and SPSS.

\section{G Open Access}

Received: 17 June 2019

Accepted: 12 August 2019

Published: 21 August 2019

Copyright $@ 2019$ by the author(s). Licensee Hapres, London, United Kingdom. This is an open access article distributed under the terms and conditions of Creative Commons Attribution Results: Anding households surveyed fit the multiple fuel model instead of energy ladder model for boiling water by shifting between different combinations of technologies and fuels, whether clean or solid fuels. Households that used PSCs year-round paid less for energy than households that did not own PSCs.

Conclusions: Anding district households successfully adopted clean cooking technology for water treatment, which suggests that other impoverished rural residents with cultural preferences for drinking boiled water and sufficient solar irradiation may adopt PSCs for an environmental and economic win. Given the Agenda 2030 Sustainable Development Goals to provide both clean water and clean cooking

\subsection{International License.}


technology access, policies integrating PSC installation alongside water supply projects are a possible way to help achieve both goals.

KEYWORDS: water purification; household energy use; parabolic solar cookers; northwestern China; energy-water nexus

\section{ABBREVIATIONS}

$\mathrm{BC}$, black carbon; $\mathrm{C}$, degrees Celsius; $\mathrm{CO}_{2}$, carbon dioxide; $\mathrm{CO}$, carbon monoxide; HICs, high-income countries; HWT, household water treatment; kJ, kilojoules; LICs, low-income countries; MJ, megajoules; m, meter(s); MDGs, Millennium Development Goals; $\mathrm{NO}_{x}$, nitrogen oxides; PM2.5, atmospheric particulate matter with diameter less than 2.5 micrometers; PSC, parabolic solar cooker; RMB, Renminbi currency of P.R. China; SDGs, Sustainable Development Goals; UN, United Nations

\section{INTRODUCTION}

Providing clean drinking water to the growing world population is a formidable challenge set by the United Nations (UN) as Goal 6 of the Sustainable Development Goals (SDGs) for 2030. Nearly 1.8 billion people worldwide lack access to clean water, and that number is expected to increase [1]. Boiling water at home is a recommended method of decentralized drinking water treatment [2]. However, approximately 3 billion people lack clean cooking energy [3]. Providing clean drinking water is an energy-water nexus problem due to the provision, costs, and affordability of energy for impoverished people who lack clean drinking water.

\section{Background}

Primarily in rural areas of low-income countries (LICs), 2.8 billion people worldwide rely on solid fuels to meet their domestic thermal energy needs, such as cooking, hot water, and home heating [4]. Reliance on solid fuels, such as wood, biomass, coal, and animal dung can be detrimental to both human and environmental health in addition to its negative socio-economic effects. Indoor air pollution caused by smoke and particulate matter from burning solid fuel is estimated to cause 4 million deaths per year-more than other highly publicized diseases in LICs, such as tuberculosis, malaria, or HIV/AIDS [5,6]. Environmental effects from the use of biomass fuel include both immediate deforestation from fuelwood collection and long-term climate change caused by the release of greenhouse gases and black carbon [7]. Additional societal impacts include the burdens and risks associated with fuel procurement and cookstove operation, which disproportionately affect women and children [8,9]. 


\section{Research questions}

The majority of Anding households used PSCs for water boiling, which is significant because efforts to promote the adoption of solar cookers have failed in many other locations around the world [10]. This research sought to understand what factors influenced Anding households to successfully adopt PSCs for water purification. Understanding what enabled PSCs to succeed in Anding will offer insight on how effective usage of this renewable energy technology can be achieved in other locations. Due to lack of existing literature about PSC use for household water boiling, this research investigates the following questions:

- Whether the energy ladder or multiple fuel model better fits Anding's household use of energy for water boiling,

- Whether energy use and costs differ between households that use PSCs and those that do not, and

- What factors and circumstances enabled the successful adoption of PSCs for water purification in Anding district.

\section{Research importance}

Since the UN established the Millennium Development Goals (MDGs) in 2000, and specifically because of Goal 7 of the SDGs to provide access to clean and affordable energy [11], many development initiatives have begun to integrate clean cooking into their agendas. Using India as a case study, Bhide and Monroy (2011) describe how energy poverty is a critical obstacle to achieving the MDGs and suggest that the role of renewable energy-including solar cookers-could be key to achieving universal access to sustainable energy [12]. Historically, households have often resisted using solar cookers despite promotion efforts that promise economic, health, and environmental benefits [10]. However, past attempts to promote solar cookers have focused almost exclusively on cooking food. Due to the prevalence of waterborne diseases and the lack of water treatment infrastructure focusing on household water purification through boiling, this research suggests that efforts to promote solar cookers specifically for water purification may lead to better utilization of the technology. This research seeks to fill the knowledge gap by comparing energy needs for household-level water purification.

\section{Literature Review}

China lacks sufficient water resources in general [13], and clean drinking water in particular, for 1.3 billion people [14]. Low-cost, energyefficient purification methods are essential to improving clean water access [14]. Stoves are an accessible household technology for purifying water through boiling. However, burning solid fuels reduces indoor air quality, contributing to human health problems [15]. Previous government initiatives have successfully improved rural household indoor air quality. For example, the China National Improved Stove 
Program positively affected nearly 65\% of rural homes in 1982-1992 [16]. Policies promoting rural household biogas digesters increased their use from 8 million to 40 million in 2001-2010 [17].

\section{Anding district}

Anding district is in Dingxi City prefecture in Gansu province, in northwestern China. It has a semi-arid climate with an average annual rainfall of 400 to 600 millimeters (about 15.75 to 23.62 inches)[18]. Water scarcity problems from groundwater salinity and lack of running water leave most residents dependent on precipitation for drinking water. Because rainfall varies greatly both seasonally and year-to-year, rainwater storage is a necessity [19]. Poverty is a particular problem because of poor soils in this predominantly agricultural region [20]. Chinese government leaders have particularly targeted poverty reduction efforts for 2020 [21] in Dingxi prefecture, where Anding is located, because poverty is exacerbated by water scarcity [22].

\section{Solar cookers}

Solar cookers are devices that concentrate and absorb sunlight to heat food and liquids. A PSC resembles a satellite dish (Figure 1A), concentrating the sun's rays onto one central target to achieve temperatures as high as $200^{\circ} \mathrm{C}$ [23]. Parabolic solar cooker design does not allow for easy adjustment of cooking speed and temperature, which can make cooking food difficult [24] but not boiling water. Successful adoption and use of solar cookers is challenging because functionality is limited to daytime hours and is further restricted by normal variations in sunshine. The user behavior of pouring boiling water into insulated bottles (Figure 1B) allows users to utilize PSCs when the sun is shining and then continue to enjoy hot water long after it has set.

(A)

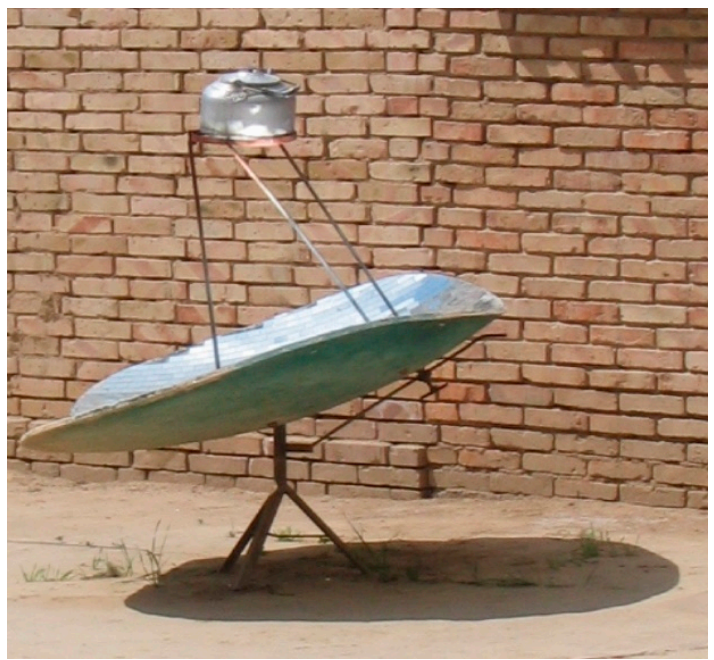

(B)

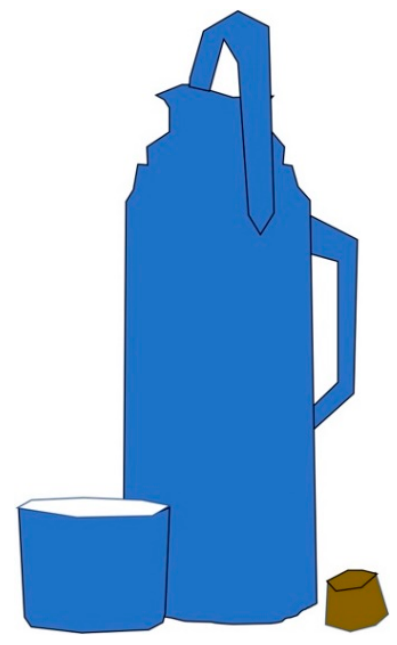

Figure 1. (A) Locally manufactured parabolic solar cooker in use in Gansu province, (B) drawing of insulated heat-retaining bottle (reshuiping) with two handles, top, and cork stopper (authors' images). 
Depending on the design, PSCs have energy efficiencies ranging from $26.6 \%$ [25] to $32.97 \%$ [23] for cooking and more than $60 \%$ for water boiling [26]. Many areas in China, including Anding district, are able to locally manufacture PSCs similar to Figure 1A from cement, mirror pieces, and metal [26]. Parabolic solar cookers may be utilized worldwide in areas with abundant and consistent sunlight. Southeast Gansu (including Anding) receives between 3.8-4.5 [27] and 4.5-5.5 $\mathrm{kWh} / \mathrm{m}^{2}$ of daily solar irradiation [28] totaling 2200-3000 h of sunshine annually. Thus, PSCs can function for 150-200 days of the year in Gansu [27].

After the initial purchase of a PSC, there is no further cost in terms of money or time spent to procure fuel. Estimates of cost reduction go as high as $36 \%$ for fuelwood substitution by solar cookers [29]. Fang \& Li (2013) report a household solar cooker can save approximately 1000 kilograms of fuelwood in China annually [27]. Although not explicitly stated, Fang \& Li's $2 \mathrm{~m}^{2}$ solar cooker is most likely a PSC due to its large size.

\section{Cultural barriers to user acceptance of PSCS}

Cultural barriers have significantly limited the use of solar cookers and must be addressed to facilitate more widespread adoption of this technology [29,30]. Most studies of the acceptance of solar cookers have been conducted by manufacturers/designers of the technology [31], which presents bias. Pro-solution biases are common in much of the academic literature on solar cookers in general [32]. Using PSCs to boil water has the benefits of convenience, cost savings, and improved health outcomes that possibly would allow PSCs to gain preference over other technology-fuel combinations for users. Yet, PSCs are unlikely to achieve acceptance for all of a user's cooking needs. Barriers to PSC use for cooking include adaptations for meal planning, longer cooking times, changes to food tastes and textures, and aversion to cooking outdoors among other concerns [10,33]. However, just as culture can prevent barriers to adoption of solar cookers, it can also play a role in fostering adoption of the technology [34]. Fewer barriers in general exist for water boiling with solar cookers than for cooking food.

Biermann et al. (1999) confirm that PSCs in South Africa are used in addition to other technology-fuel combinations. Furthermore, Biermann et al. find that household acceptance and use of solar cookers is added on top of other cooking technologies (approximately 2.5 cooking options per household) that are powered by a variety of fuels [31]. Parabolic solar cookers can be the preferred technology for boiling water in rural homes even if they do not work $100 \%$ of the time; other water boiling methods are on hand for when solar cooking is impractical. A versatile portfolio of technology-fuel options can meet many of a household's energy needs, making PSCs viable for water purification. 


\section{Energy ladder versus multiple fuel use model}

The energy ladder model of cooking fuels labels fuels on a continuum from inconvenient and dirty for the user to convenient and clean, with electricity at the apex. However, electricity generation, especially from coal, can create regional air pollution problems even though it does not cause indoor air pollution problems in the home. Electricity generated from solar or wind resources does not create air pollution during use and so is labeled as a cleaner fuel in Figure 2. Solar and biogas are notably absent in several articles about the energy ladder, e.g., [35-37]. The energy ladder presented in [38] has been revised in Figure 2 to include these renewable energy sources, and reflects the relative population size of different income levels around the world based on World Bank PovcalNet data [39]. Spacing between income brackets in Figure 2 represents relative proportion of people worldwide. Darker colors represent higher demandside emission rates, and lighter colors represent lower demand-side emission rates.

A Global Alliance for Clean Cookstoves report by Cashman et al (2016)[40] ranks energy sources for cooking in China by average emission factor for $\mathrm{CO}_{2}$, $\mathrm{CO}$, methane, $\mathrm{NO}_{x}$, and $\mathrm{PM} 2.5$ in weight/joule from highest to lowest. This ranking from dirty to clean is displayed in Figure 2 as unprocessed biomass (black), fossil (solid) (dark grey), processed solid biomass (medium gray), liquid/gas (light gray), and other (white). Figure 2 takes a conservative approach to evaluating biogas as an energy source with regards to emissions. Regional differences in cultivation of biogas inputs impact whether net emissions exist [41]. Methane leaks from household biogas can vary by digester type, and the overall emission reductions achieved are affected by the type of fuel for which it serves as a substitute [42,43].

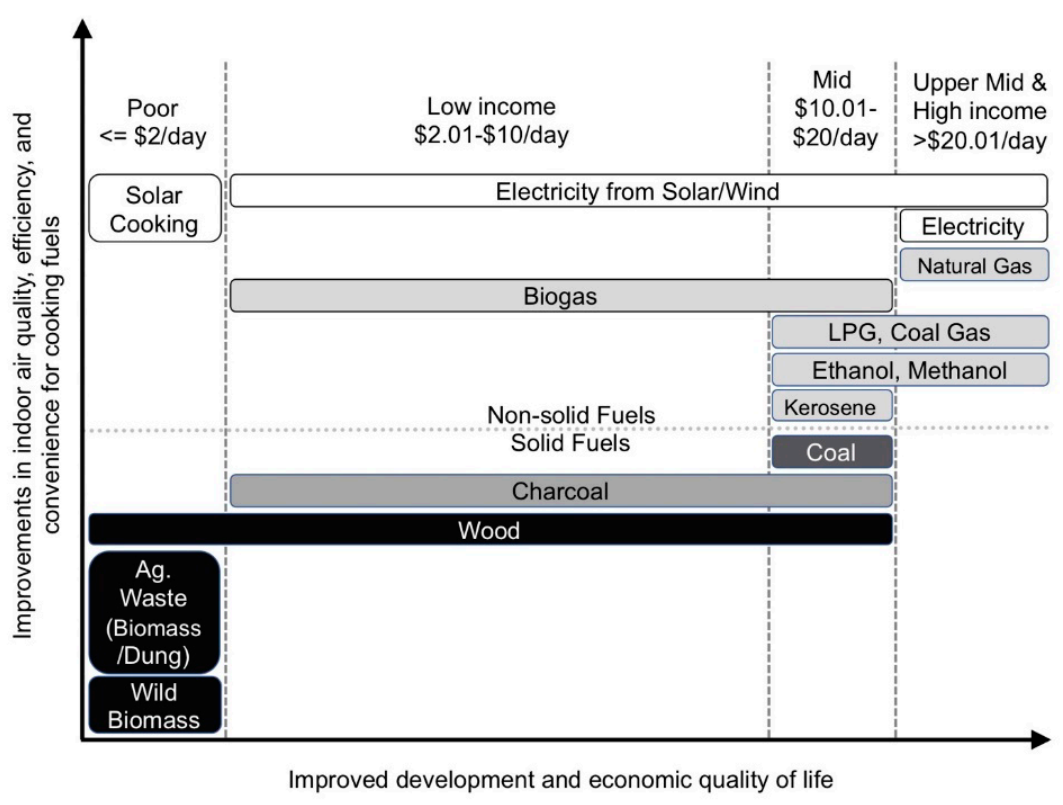

Figure 2. The Energy Ladder adapted from Rehfuess (2006) [38] to include solar and biogas energy. 
Although unidirectional vertical movement up the energy ladder has been observed in most higher-income countries (HICs) to fulfill ordinary household cooking requirements, the model has been less conclusive in LICs. Instead, Masera et al. (2000) describe the "multiple fuel model” where households incorporate higher-tier energy sources alongside traditional firewood and suggest that multiple fuel scenarios are more common than singular fuel sources in LICs [36]. van der Kroon et al. (2013) conclude that existing data does not support the energy ladder model [37], arguing that users with more income incorporate greater varieties of energy types into their household energy portfolio.

\section{Household energy use in northwest China}

In 2006, Li et al. (2009)[44] surveyed rural households in two Gansu counties, Tongwei and Qin'an, which are directly southwest of Anding. They found that the average household utilizes nearly $45 \%$ of its energy for cooking and boiling water, and that cleaner energy sources (defined as solar, electricity, biogas, and LPG) total nearly $10 \%$ of household energy supply. Niu et al. (2014)[45] surveyed households in two Gansu counties in 2012 and found that solar is among the various fuels in use that have a quick economic return of two years or less. In addition, Tonooka et al (2006)[46] surveyed household energy use outside of Xi'an in Shaanxi province, near Gansu, and found that over half of households used at least two stoves and that a variety of fuels were used including biomass, biogas, charcoal, coal, electricity, and LPG. However, they did not consider appliances such as electric teakettles or PSCs that were used to boil water. Previous work by Clarke-Sather, Li, and Qu considered carbon reduction strategies from household lighting energy use changes in Anding district [47].

\section{Contribution to the field}

A rural household energy survey in Anding district revealed a variety of cooking technologies used to boil water for purification. Water boiling technologies included those powered by fossil fuels such as gas or coal stoves, electric appliances, renewable energy powered options such as biogas or biomass stoves, and PSCs. This research identified specific cultural, climate, environmental, geographical, socio-technical, ease of use, user behavior, and economic factors that support the successful adoption of PSCs for water purification by the majority of households surveyed. Recognizing a deficit of literature offering quantitative evidence of widespread use of PSCs to boil water, the authors recommend integrating solar technologies with water programs in LICs where these factors aiding successful adoption are found. 


\section{MATERIALS AND METHODS}

Data concerning rural energy use from Anding households was gathered using a questionnaire developed and refined by A. R. ClarkeSather, J. Qu and students from Lanzhou University through in-person pilot surveys. A key difference was noted during the analysis of the survey data: use of PSCs as compared to other technology-fuel options for water boiling. The surveyed households were divided into groups defined by PSC use. Data was analyzed using a Pearson's chi-squared test [48] and one-way analysis of variance (one-way ANOVA)[49] with Tukey post hoc testing to compare whether differences existed between groups' expected and observed frequency [48] and the means of multiple groups [50].

\section{Data Collection}

Data for this research was obtained through household energy and water use surveys completed in August 2010 in Anding district [47]. On July 27th, 2010 A. R. Clarke-Sather and J. Qu obtained permissions from a Human Subjects Review Committee at the Lanzhou branch of the Chinese Academy of Sciences (CAS) for the project entitled "Environmental life cycle assessment and efficient use of energy resources" that encompasses human subjects research data analyzed in this paper and in [47]. Researchers surveyed more than $10 \%(n=237)$ of the 2300 households in 36 neighborhoods within five towns. Three teams of two students conducted each survey in Mandarin Chinese. The students were at the graduate (1), undergraduate (4), and high school (1) level. Only household respondents who voluntarily agreed to participate were surveyed.

To obtain survey responses from a randomized sampling of households, researchers received a list of residential addresses from a neighborhood leader, town mayor, or another government official. Research teams surveyed every 10th household from that list, for example by visiting the third, 13th, and 23rd household listed. If an adult (age 18 or older) was not willing or available to participate at a designated household, the survey team moved to the house before or after it on the list. Local officials were not involved in the selection of which households to survey. Household residents were not pressured to participate, nor to answer any questions they preferred not to answer. A more detailed description of this method is available in previous work [47]. This randomized household sampling approach is used for research in other parts of the world, including the U.S. [51].

\section{Data Analysis}

Energy and water use data self-reported by household survey respondents in all five towns was considered together. All water purification occurred by boiling, although different technologies and fuels were used to do so (Table 1). A key energy and water use difference among households was when and if PSCs were used to boil water. The households 
were divided into four groups defined by PSC use or the lack thereof (Table 1). Of the 237 households surveyed, 198 (84\%) responded that they owned PSCs. None of these PSCs were purchased with the help of the Appliances to the Countryside rural economic development program, which ran from 2009 to 2013 [52], although other appliances such as freezers were purchased by Anding households using this program (Appendix A1). The survey results showed that PSCs were purchased by household residents without government financial assistance. Over 58\% of households (139) reported using PSCs either all year or in summer only. For this reason, households were aggregated into four categories of PSC use: All Year, Summer Only, No PSC Use (own but do not use), or No PSC (do not own). Key differences among households in their annual use of PSCs for water boiling - and the four user groups created to reflect those differences-form the units of comparison to answer all research questions posited.

\section{Water boiling technology-fuel combinations}

Table 1 shows the specific technology-fuel combinations used by each PSC user group to boil water. Technology-fuel combinations were analyzed because a technology such as a solid fuel burning heat stove (luzi) can be used with more than one type of fuel, e.g., coal and/or biomass. Households often use more than one technology-fuel combination. All groups utilize multiple fuels, both clean and dirty as described by the energy ladder found in Figure 2. The total number of households in each PSC user group is labeled on the top row. For the groups that do not have or do not use PSCs, the most common technology-fuel option was a stove burning coal or a stove burning biomass.

Table 1. Number of households with different technology-fuel combinations for water boiling by PSC user group.

\begin{tabular}{lccccc}
\hline Technology-fuel combination & $\begin{array}{c}\text { All Year } \\
(\mathbf{1 1 0})\end{array}$ & $\begin{array}{c}\text { Summer } \\
\text { Only (29) }\end{array}$ & $\begin{array}{c}\text { No PSC } \\
\text { Use (66) }\end{array}$ & $\begin{array}{c}\text { No PSC } \\
\mathbf{( 3 2 )}\end{array}$ & $\begin{array}{c}\text { Total Households } \\
\text { (237) }\end{array}$ \\
\hline Stove (luzi) coal & 49 & 14 & 35 & 15 & 113 \\
Stove (luzi) biomass & 48 & 15 & 22 & 12 & 97 \\
Electric tea kettle & 20 & 6 & 11 & 8 & 45 \\
Stove (zao) biogas & 22 & 5 & 15 & 1 & 43 \\
Stove (luzi) biomass \& coal & 13 & 4 & 13 & 6 & 36 \\
Water cooler (purifier) & 12 & 0 & 6 & 2 & 20 \\
Stove (zao) gas & 2 & 0 & 1 & 1 & 4 \\
Stove (luzi) biomass \& gas & 1 & 0 & 1 & 0 & 2 \\
Stove (luzi) biomass \& manure & 2 & 0 & 0 & 0 & 2 \\
Stove (luzi) coal \& gas & 0 & 0 & 1 & 0 & 1 \\
Stove (luzi) Biomass, coal \& gas & 0 & 0 & 1 & 0 & 1 \\
\# of Technology-fuel combinations used & 169 & 44 & 106 & 45 & 364 \\
\hline
\end{tabular}


Figure 3 shows the number of technology-fuel used by households to boil water. The majority of Anding households $(n=209)$ use between one and three technologies to boil water, with an average of 2.2 technologyfuel combinations $(n=228)$. The most common number of water-boiling technologies used in a household was two.

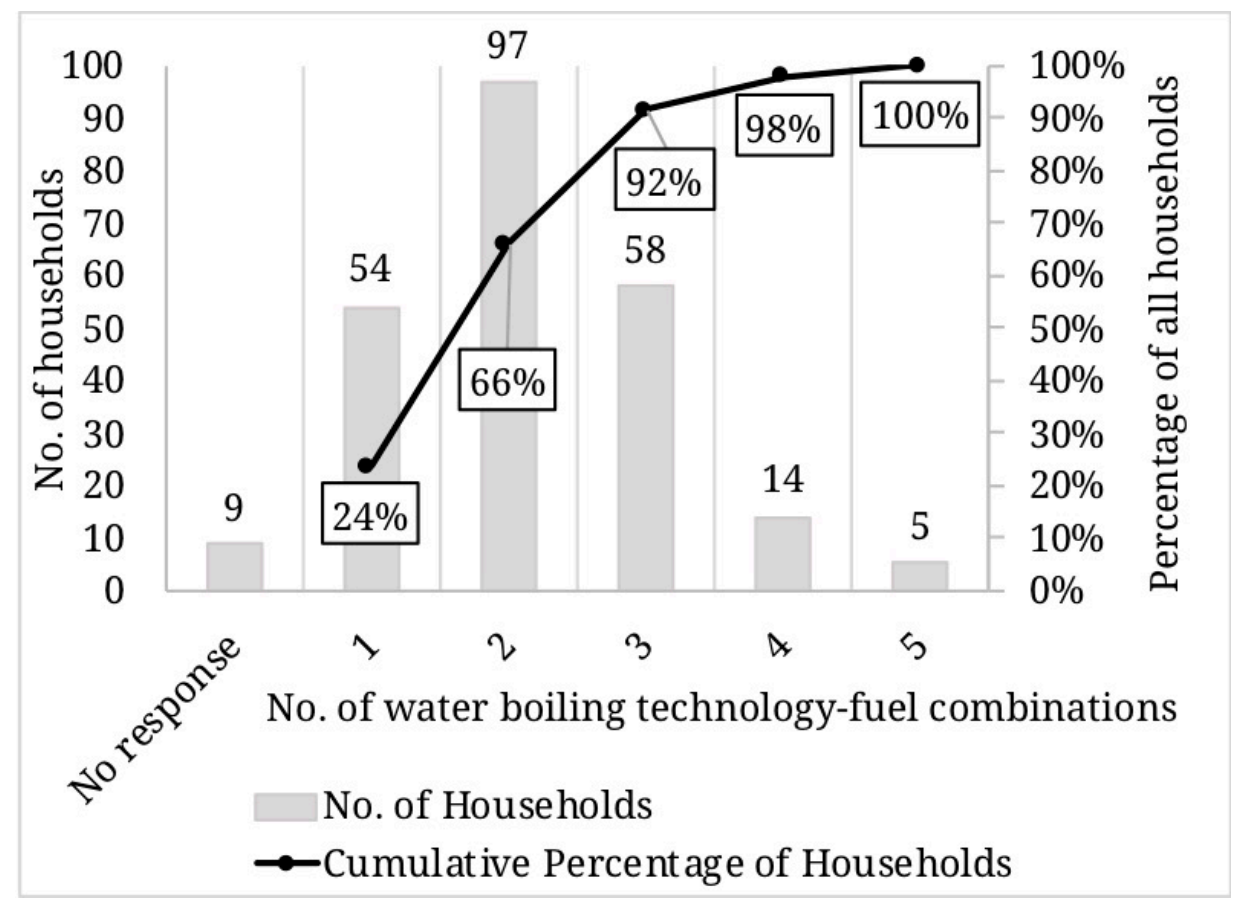

Figure 3. Number of technology-fuel combinations used by all Anding households. Line denotes cumulative percentage of households with that number of technology-fuel combinations.

\section{PSC user groups}

Figure 4 shows the number of households in each PSC user group. The All Year group denotes PSC use for water boiling in both summer and winter. The Summer Only user group denotes households that use PSCs for water boiling only in summer. The No PSC Use group denotes households with a PSC that is either broken $(n=5)$ or for other reasons stated $(n=2)$ or unstated not in use. The No PSC user group denotes households that either had no PSC or did not respond to the question about PSCs. Summer is defined as occurring from April through September (183 days), and winter as October through March (182 days). All survey responses were analyzed for differences among households in terms of their use of PSCs to boil water. 


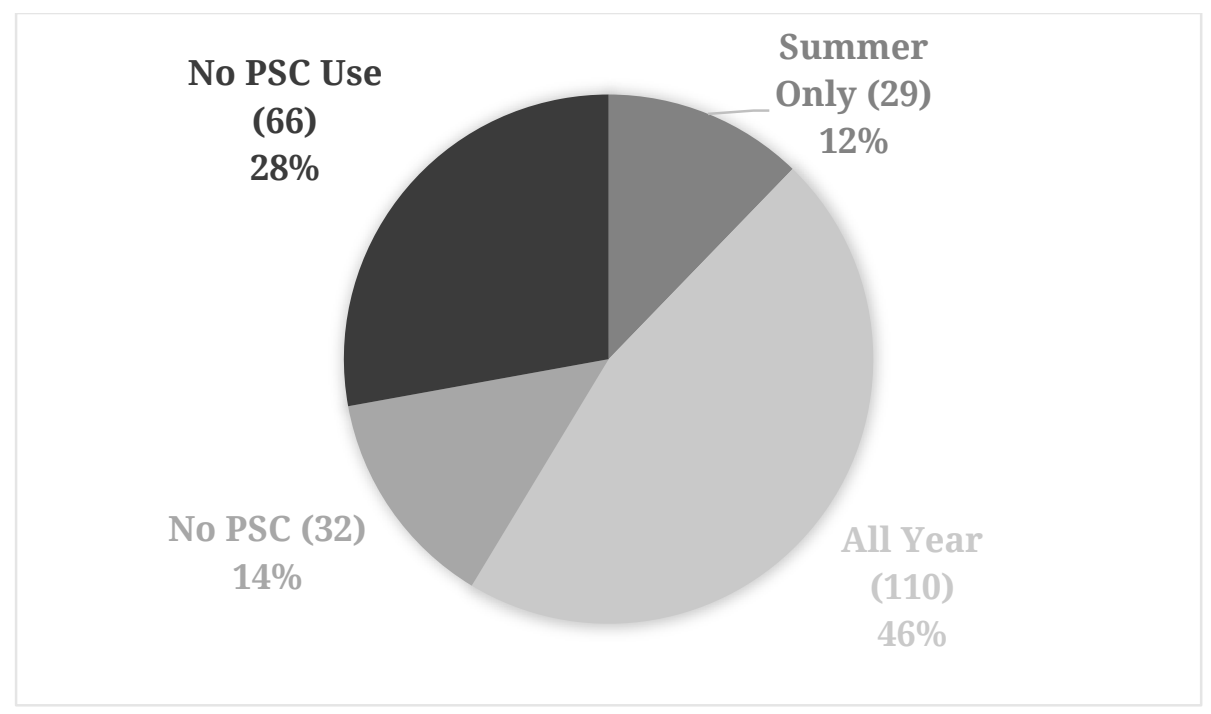

Figure 4. Number and percentage of surveyed Anding district households in different PSC user groups.

\section{Statistical analysis method}

SAS Institute JMP Pro 14.0 was used to calculate a Pearson's chi-squared statistic to compare whether the PSC user groups created (All Year, Summer Only, No PSC Use, No PSC) were independent of each other and whether these groups had a relationship to the PSC use seasonally of survey respondents (summer, all year, and no use). The chi-square statistic specifically considers whether there is a difference between an expected normal and random distribution of the variables and what was observed, which is commonly interpreted as independence between variables [48].

A one-way ANOVA was used to compare averages and identify differences among the groups. A one-way ANOVA is used in place of a $t$-test when there are means from more than two groups to compare regarding a single dependent variable [49]. Because the dataset considered four groups, a one-way ANOVA was necessary for comparing the groups' mean energy use and costs. The Tukey post hoc test was used to compare individual differences found between the means of different groups [50]. All statistics were described as showing significant difference at a $95 \%$ confidence level, i.e., $p<0.05$.

IBM SPSS Statistics 24 software was used to carry out statistical analysis of the one-way ANOVA where the following assumptions had to be valid:

1. The dependent variable should be measured at the interval or ratio level

2. The independent variable consists of two or more categorical, independent groups

3. There is independence of observations

4. There are no significant outliers

5. The dependent variable is approximately normally distributed for each category of independent variable

6. There is homogeneity of variances 
Assumptions 1 through 4 were verified analyzing the data in MS Excel. For Assumption 5, the Shapiro-Wilk test was used to test for normality [53]. The Shapiro-Wilk test generated a Normal Q-Q plot for each solar user group where most points on each plot fit on the line of best fit for expected normal. For Assumption 6, Levene's test was run to determine whether homogeneity of variances exist [54].

\section{RESULTS}

Households in the Anding district use a combination of technologies and fuels for different energy end use purposes. Figure 4 shows the energy end uses in white boxes surrounded by fuel/energy types used by Anding district households. Drinking water purification was achieved through boiling. Boiled water was stored in large insulated heat-retaining bottles for later use (Figure 1B), a common practice across China. Figure 5 shows that any type of fuel or energy used by households in Anding district may sometimes be used for water purification purposes. Fuel or technology substitution in the Anding district households may occur for the purpose of water purification. The Anding households surveyed used PSCs solely for boiling water.

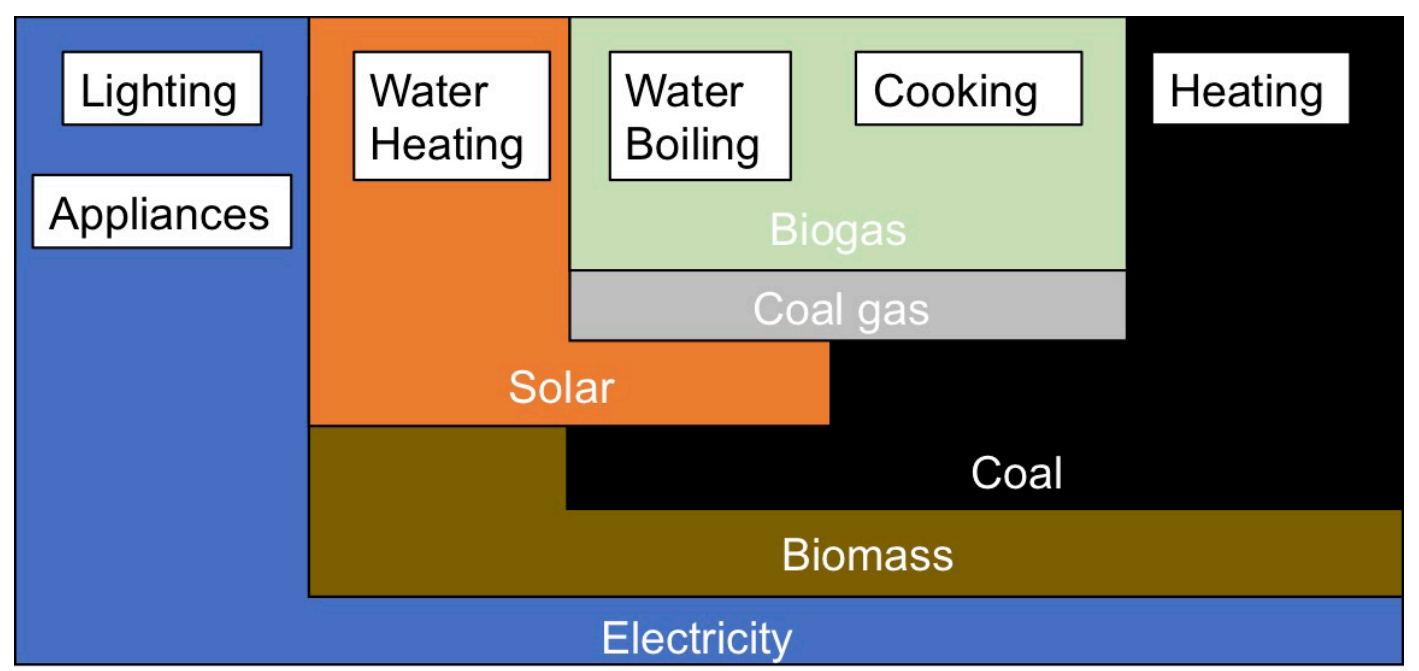

Figure 5. Energy end use purposes (white boxes) that are met by different types of fuel/energy used in Anding district.

Two types of stove technology were used in Anding district households, luzi (home heating stoves that can only burn solid fuels; Figure 6A) and Zao (cooking stoves that can only burn gaseous fuels; Figure 6B). Both types of stoves were used for boiling water in surveyed Anding district households. 
(A)

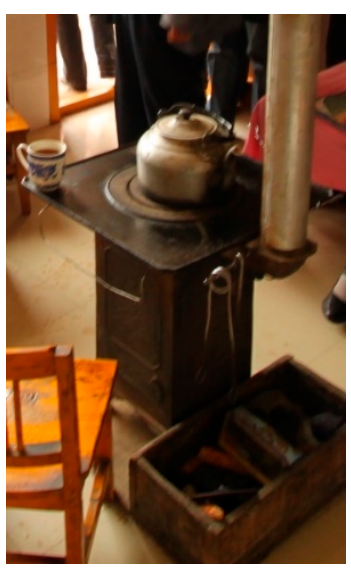

(B)

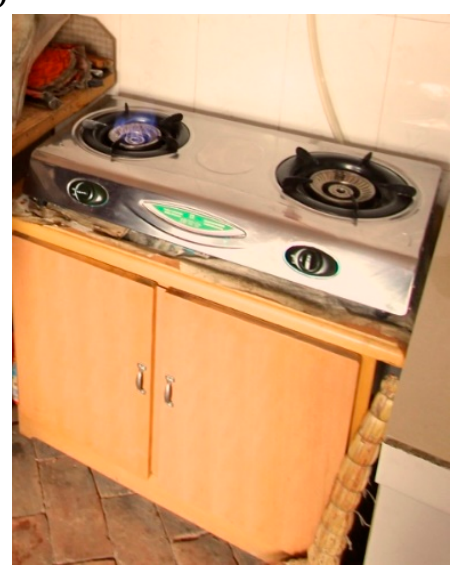

Figure 6. (A) Home heating stove (luzi) with adjacent coal bin and (B) biogas two-burner cookstove (zao) from Anding district (authors' photographs).

Many homes in Anding have a traditional design wherein each room opens onto a sunlit courtyard. Other households reside in small apartment buildings with enough space and sunlight for multiple PSCs in the yard or rooftop areas. Disrepair of the PSCs was a barrier for some households because welding, metalwork, or cement work may have been required to make repairs. Inconvenience, such as the need to plan ahead to boil water, was also a barrier. The average age of PSCs in Anding district was 6.74 years old $(n=197)$ with a median age of 6 and mode of 10 years old across 197 responding households (see Appendix A4). Thus, PSCs were not new technologies being used in Anding district and the novelty of the technology had likely little influence on PSC use.

Table 2 describes differences in household groups' PSC energy use. Households were asked about frequency of use for the solar stove and twenty other household appliances as well. Respondents varied in the details of their answers in responding to this question. On the more detailed level, one respondent reported using the solar stove 20 days out of each month throughout the year, and another respondent reported using the stove for $3 \mathrm{~h}$ every day in the summer. On the less detailed end, three different respondents reported using their stoves every day when there is sun, every day in the summer, and every day, respectively. An assumption was made from less detailed information to add those who reported using their solar stoves when there is sun or every day into the all year category at 150 days per year from information given in [27]. Similarly, it was assumed that 75 of those days occurred in summer and 75 in winter, which is a reasonable assumption in the semi-arid climate of Anding district.

Pearson's chi-squared statistic was calculated to compare whether the PSC user groups created (All Year, Summer Only, No PSC Use, No PSC) were independent and had a relation to the PSC use seasonally of survey respondents (summer, all year, and no use). The chi-square statistic specifically considers whether there is a difference between an expected 
normal and random distribution of the variables and what was observed, which is commonly interpreted as independence between variables [48]. The $\mathrm{p}$ values for Pearson's chi-squared test was $<0.0001$, which can be interpreted as that the variables differed from what would be expected from normal or random data and thus are independent (Appendix A2 shows the contingency analysis table for this statistic). A post hoc test was run to compare PSC user groups as pairs for the same Pearson's chisquared statistic. All of the paired groups also had $p<0.0001$, except for the No PSC Use and No PSC group. A chi-squared statistic could not be calculated for the latter two groups because the responses from both the No PSC Use and No PSC groups were the same. The reason for separating these two groups does not come from statistics, but rather from the fact that the households without PSCs had no opportunity to use a PSC as an alternative (hence the No PSC group). However, the households that owned a PSC but chose not to use the PSC did have that alternative and chose not to use their PSCs. The No PSC and No PSC Use groups had different opportunities, although the same end result of no PSC use. All four groups are needed to compare the different choices households made relative to their access to and user behavior choices about whether to or whether not to use PSCs.

The solar energy use for water boiling was calculated using the following two assumptions. First, one standard size teapot is 3.6 liters in volume and 355 kilojoules $(\mathrm{kJ})$ is needed to boil one liter of water. Over $70 \%$ of households surveyed in Anding use teapots of this size, shown in Figures 1 and 6A. Second, each household was assumed to boil one teapot of water per day (1281 kJ). On average, the households surveyed boiled between 5.5 liters of water per day in winter and 8.5 liters of water per day in summer, which corresponds to 2 to 3 standard teapots. The solar energy estimated energy use was conservative and likely underestimated the amount of solar energy used because of the assumptions about how much water was boiled using solar stoves. The number of days PSCs were used annually was based on [27].

Table 2. Average PSC use by summer, winter, and annually by PSC user group.

\begin{tabular}{lccccc}
\hline PSC use & All Year & Summer & No PSC & No PSC & All Households \\
& $\mathbf{( 1 1 0 )}$ & Only (29) & Use (66) & (32) & (237) \\
\hline Average summer PSC use (MJ per person-year) & 41.32 & 41.15 & 0.00 & 0.00 & 24.21 \\
Average winter PSC use (MJ per person-year) & 41.32 & 0.00 & 0.00 & 0.00 & 19.18 \\
Average annual PSC use (MJ per person-year) & 82.63 & 41.15 & 0.00 & 0.00 & 43.39 \\
Average PSC summer use days per year & 75.00 & 76.55 & 0.00 & 0.00 & 44.18 \\
Average PSC winter use days per year & 75.00 & 0.00 & 0.00 & 0.00 & 34.81 \\
Average PSC all year use days per year & 150.00 & 76.55 & 0.00 & 0.00 & 78.99 \\
\hline
\end{tabular}

Many rural residents have their official household status (hukou) in a rural area but live, work, and/or go to school for the majority of the year in an urban area. Therefore, to avoid misinterpretation of household energy use the authors did not use a per capita energy use measure. A per 
capita energy use measure would deflate household energy use values per person because it would ignore the amount of time rural residents spend in their rural household each year. As an alternative to a per capita energy use measure, the number of residents residing in a household was multiplied by the percentage of the year the residents lived in the home to derive a person-year measure. For greater accuracy, all energy use is compared per person-year instead of per capita.

The Summer Only and All Year groups differed significantly from one another in their PSC use, while the No PSC Use and No PSC groups did not. However, both the No PSC Use and No PSC groups showed statistically significant differences from the Summer Only and All Year groups. Despite the lack of difference between the No PSC Use and No PSC groups, all four user groups were retained in the analysis. Statistically significant differences in other energy and water use characteristics were found between the No PSC Use and the No PSC groups, suggesting a genuine difference between these groups apart from owning or not owning a PSC.

Seasonal differences (defined as $p<0.05$ ) exist among user groups in the amount of solar energy used for boiling water. Thus there are distinct energy user groups for water boiling amongst Anding households, which are distinguished by their differing PSC energy use. For each of the four user groups, Table 2 shows the one-way ANOVA results for summer and winter differences in PSC energy use in megajoules per person-year. All groups differ from the Summer Only group for summertime solar energy use. All groups differ from the All Year group in wintertime solar energy use. The Summer Only, All Year, and No PSC Use groups differ significantly in summertime PSC use. The Summer Only, No PSC Use, and No PSC groups do not differ significantly in terms of wintertime solar energy use, which is expected because these groups do not use PSCs in the winter. The analysis in Table 2 justifies the comparison of these four user groups for differences based on PSC use.

\section{Household Drinking Water Access and Use}

None of the 237 households surveyed had running water. Nearly 95\% of households had at least one water cellar, where rainwater collects in an underground water storage tank and is pulled up with a bucket or an electric pump. Most households in rural northwest China, including Anding district, also store water in large ceramic crocks in the kitchen, where it is ladled out to be boiled for drinking [19]. Thus, water is at room temperature when the boiling process begins.

\section{Seasonal variation}

Seasonal differences exist in the quantity of water consumed for drinking. With the exception of the No PSC group, a paired t-test shows a noticeable seasonal difference between summer and winter water use for all PSC groups (Table 2). Households in the All Year, Summer Only, and No PSC Use groups consume more boiled water during the summer (Figure 7), 
demonstrating a seasonal difference in energy use for water purification. All energy calculations for water boiling in households was divided per liter to allow accurate comparison of the impacts of different technologyfuel energy use choices. A conservative estimate is that three teapots of water could be boiled per day on a PSC in Anding district when the sun was shining (see Appendix A3 for calculations).

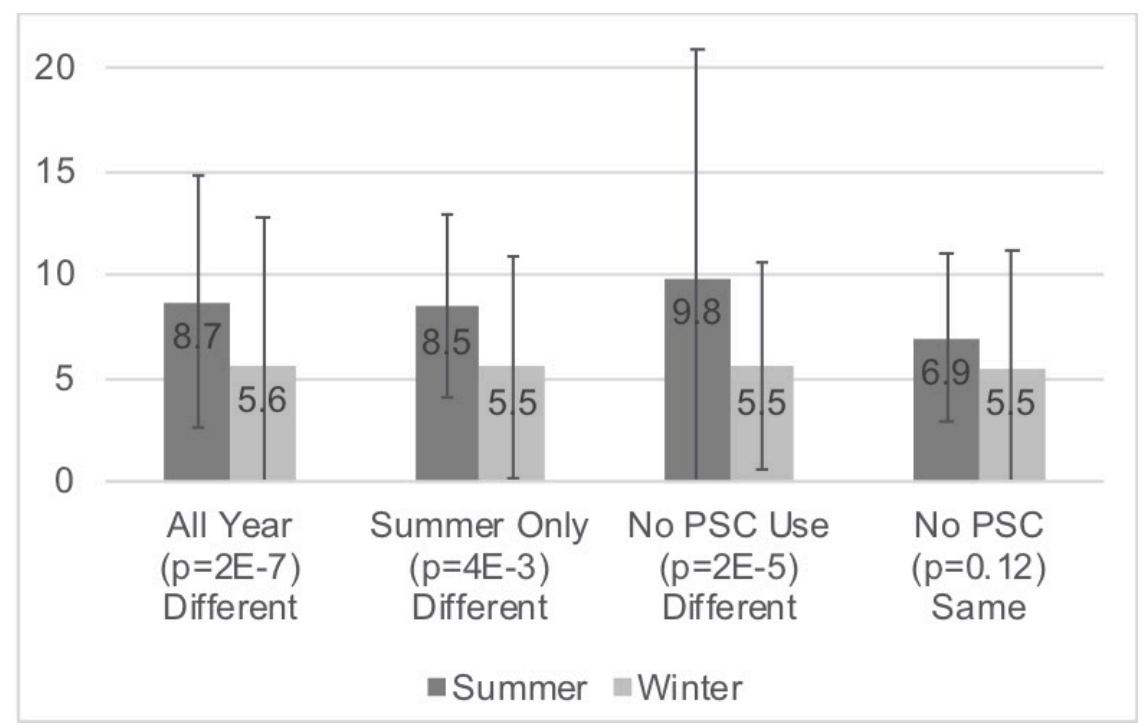

Figure 7. The four user groups and their average daily boiled water use in liters seasonally, standard deviation denoted by bars.

Technologies besides PSCs were required to satisfy all of a household's water boiling needs during cloudy days. Figure 8 shows the number of seasonal stove and fuel combinations $(n=295)$ used by the households that responded that they used stoves for boiling water $(n=230)$. Figure 8 also shows two electric appliances used to boil water, electric tea kettles ( $n=47)$ were used in 45 households and water coolers (purifiers) $(n=21)$ were used in 20 households. Some households used more than one stove or appliance to boil water. Stoves that burned biomass in summer or all year were the most common options used by households. Electric tea kettles were the second most common option used by households to boil water. Stoves that burned both biomass and coal in summer were the next most common options used by households followed by water coolers (purifiers). 


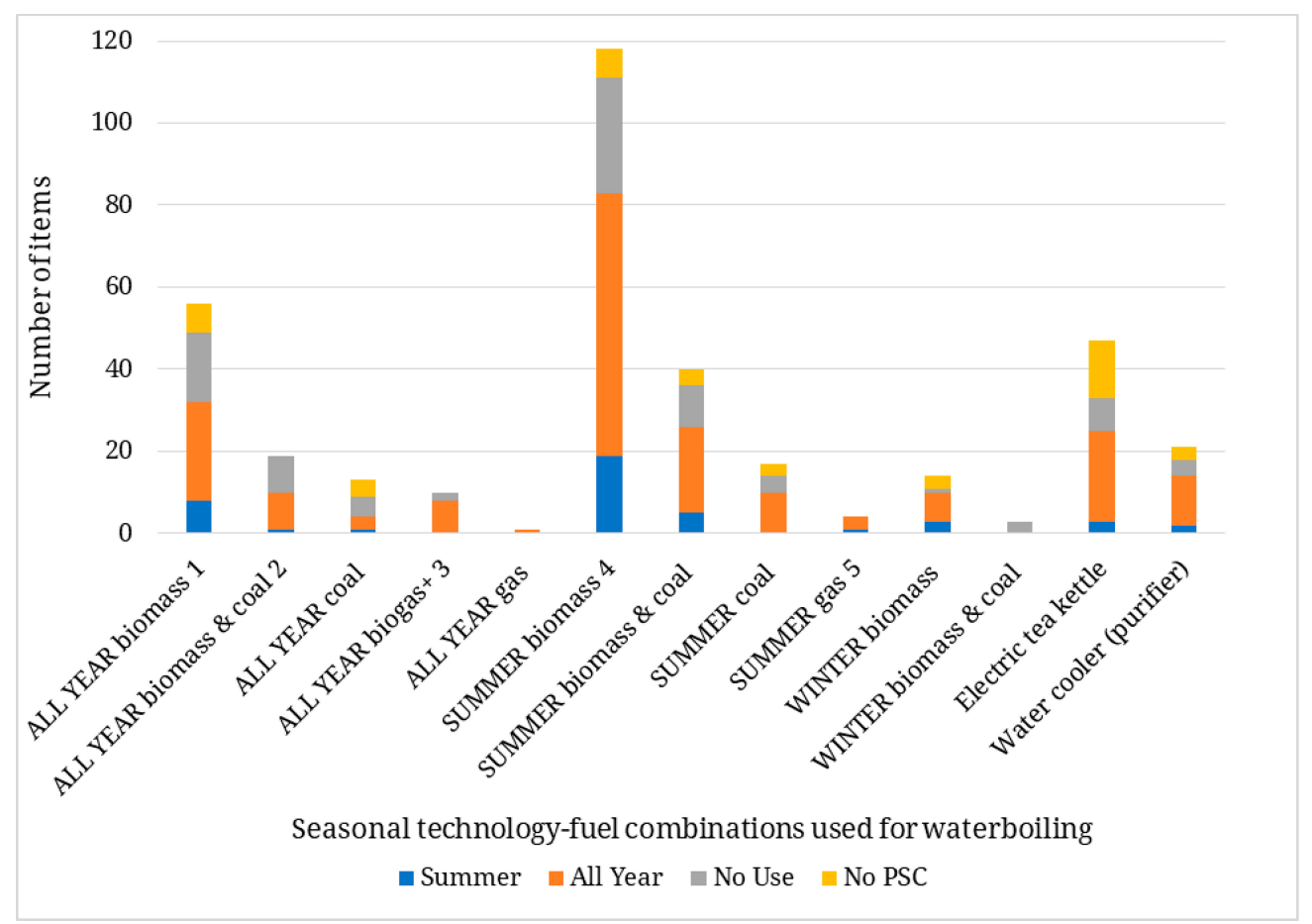

Figure 8. Stove and electric appliance technology-fuel combinations used for water boiling. (1) one household used gas, two households used manure in addition to biomass all year; (2) one household used gas in addition to biomass and coal all year; (3) all households used different seasonal combinations of biomass, coal, and gas in addition to biogas all year; (4) two households used gas in addition to biomass in the summer; (5) one household used biogas in addition to gas in the summer.

\section{Household Energy Use and Costs}

Anding households use more than one technology-fuel combination. These technologies and fuels are a combination of dirty and clean fuels found on the energy ladder. Table 3 shows the total annual average household use of different types of energy in typical units. Coal is the largest source of energy used in Anding households, followed by electricity.

Table 3. Annual average energy use by fuel type for PSC user groups in typical units.

\begin{tabular}{|c|c|c|c|c|c|}
\hline Household Energy Use & $\begin{array}{c}\text { All Year } \\
(110)\end{array}$ & $\begin{array}{l}\text { Summer } \\
\text { Only (29) }\end{array}$ & $\begin{array}{l}\text { No PSC } \\
\text { Use (66) } \\
\end{array}$ & $\begin{array}{c}\text { No PSC } \\
(32) \\
\end{array}$ & $\begin{array}{c}\text { All Households } \\
\text { (237) }\end{array}$ \\
\hline Coal (tons/year) & 1.5 & 1.4 & 1.4 & 1.5 & 1.5 \\
\hline Electricity (kWh/year) & 82.8 & 91.7 & 76.0 & 108.8 & 85.5 \\
\hline Total Biogas use summer (h/day) & 13.3 & 6.3 & 2.8 & 0.0 & 7.7 \\
\hline Total Biogas use winter (h/day) & 5.7 & 5.2 & 2.3 & 0.0 & 3.9 \\
\hline No. person-years/household & 3.0 & 3.1 & 3.4 & 2.5 & 3.1 \\
\hline
\end{tabular}

The poverty line in China is defined as annual income less than 2100 RMB. In 2010 there were approximately 6.6 RMB to the US dollar [55]. Over $40 \%$ of Anding residents were living below the poverty line in 2011 [56]. Thus, money spent on energy by Anding households represents decision-making and weighing tradeoffs between energy types. Anding households spend more money on coal than any other fuel, followed by 
electricity. Figure 9 shows the money spent on different fuel types by each user group. These monetary values include household expenditures for all energy use purposes, including water boiling.

Coal gas purchases differ significantly (defined as $p<0.05$ ) between the No PSC user group and all other user groups. Households without PSCs were found to be more likely to purchase coal gas (Figure 9). Coal gas purchases for the No PSC user group were 34.8 RMB per person-year versus zero to $3.3 \mathrm{RMB}$ per person-year for the other user groups.

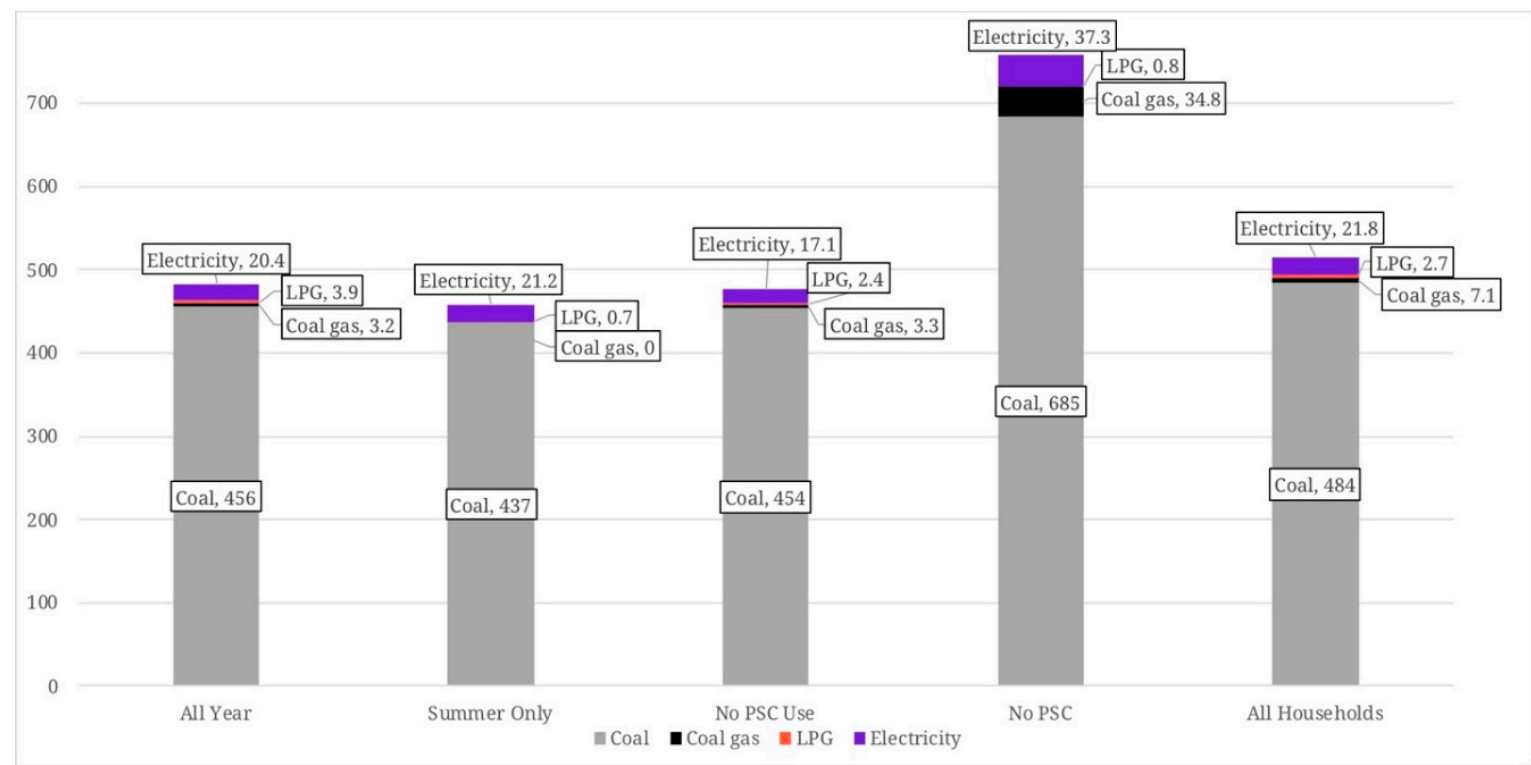

Figure 9. Average annual energy costs by fuel type in RMB per person-year for PSC user groups.

The All Year PSC user group and No PSC user group differ significantly in energy expenditures in RMB per person-year (Table 4). The average cost of total purchased energy for the All Year group is 484 RMB per personyear, compared to $758 \mathrm{RMB}$ per person-year for the No PSC group (Table 4).

Table 4. Annual average energy expenditures ${ }^{1}$ by fuel type for PSC user groups.

\begin{tabular}{lccccc}
\hline Energy Costs & All Year & Summer & No PSC Use & No PSC & \multicolumn{2}{c}{ All Households } \\
& $\mathbf{( 1 1 0 )}$ & Only (29) & (66) & (32) & (237) \\
\hline Coal & 456 & 437 & 454 & 685 & 484 \\
Coal gas & 3.2 & 0 & 3.3 & 34.8 & 7.1 \\
LPG & 3.9 & 0.7 & 2.4 & 0.8 & 2.7 \\
Electricity & 20.4 & 21.2 & 17.1 & 37.3 & 21.8 \\
Household (RMB per person-year) & 484 & 458 & 476 & 758 & 515 \\
Household Total (RMB) & 1154 & 1149 & 1070 & 1217 & 1138 \\
\hline
\end{tabular}

${ }^{1}$ In 2010 there were approximately 6.6 RMB to the US dollar.

\section{Household Energy Use}

Table 5 shows the annual household energy use in megajoules (MJ) for all energy use purposes by type of energy for each PSC user group. Coal is 
by far the largest source of energy used by all user groups. Renewable energy, mainly in the form of PSC use and also including biogas, is the second largest energy source used. Biomass used by Anding households includes agricultural waste (e.g., corn stalks and cobs) as well as wild plants. It was not possible to estimate the energy content in MJ of the dozen plus types of biomass used by Anding households with the survey data alone. Parabolic solar cooker use is highly underestimated in these results. Surveyed Anding district households stated how many days per year they used a PSC, not the total number of hours. As previously discussed, all MJ estimates for solar energy are based on boiling one 3.6 liter teapot of water per day of use, which is much less than average daily water consumption (Figure 6). Summer Only and All Year PSC user groups differ significantly from all other user groups in terms of household renewable energy use. The No PSC Use and No PSC user groups do not differ significantly due to lack of PSC use.

Table 5. Annual average energy use by fuel type in MJ per person-year for PSC user groups.

\begin{tabular}{lccccc}
\hline MJ/person-year & All Year (110) & Summer Only (29) & No PSC Use (66) & No PSC (32) & $\begin{array}{c}\text { All Households } \\
\text { (237) }\end{array}$ \\
\hline Coal & 24,731 & 13,557 & 14,722 & 22,362 & 20,257 \\
Coal gas & 11.92 & 0.00 & 11.64 & 122.34 & 25.29 \\
LPG & 25.52 & 15.56 & 8.71 & 11.75 & 17.76 \\
Electricity & 10.42 & 9.22 & 9.14 & 19.02 & 11.08 \\
Biogas & 0.32 & 0.11 & 0.09 & 0.00 & 0.19 \\
PSC-summer & 41.32 & 41.15 & 0.00 & 0.00 & 24.21 \\
PSC-winter & 41.32 & 0.00 & 0.00 & 0.00 & 19.18 \\
PSC-annual & 82.63 & 41.15 & 0.00 & 0.00 & 43.39 \\
Renewable energy & 82.75 & 41.17 & 0.03 & 0.00 & 43.46 \\
Purchased energy & 15,821 & 13,581 & 14,752 & 22,812 & 16,193 \\
\hline
\end{tabular}

${ }^{1}$ Renewable energy includes solar and biogas use.

\section{DISCUSSION}

Despite the importance of clean cooking technologies in achieving the Agenda 2030 Sustainable Development goals, widespread adoption of PSCs and similar technologies have met many challenges that have yet to be overcome. Otte (2013)[10] asserts that the successful adoption of solar cookers is dependent on cultural, technical, social, environmental and economic factors. These same factors are discussed in slightly different terms for Anding district below.

- Cultural appropriateness (cultural factors)

- Seasonal differences, ease of use, and multiple fuel use (socio-technical factors)

- Environmental and human health benefits (environmental factors)

- Energy cost reductions (economic factors) 


\section{Cultural Appropriateness}

In Anding district and China in general, drinking hot water after it has been boiled is the cultural norm and expectation [14,57,58]. Additionally, water boiling is the only water treatment employed for purification. Thus, the practice of boiling water in northwestern China is an important culturally engrained behavior, which not only protects health but also has significant implications for overall household energy use.

\section{Seasonal Differences}

Despite very different winter and summer outdoor temperatures, sunlight was sufficient to allow year-round use of PSCs by more than 58\% of households surveyed $(n=139)$ in Anding district. Water use, and thus energy use for water boiling, varied significantly by season. Three out of the four user groups consumed more water during summer than in winter (Figure 6). This difference in seasonal drinking water consumption is likely due to increased dehydration from hotter ambient temperatures in the summer. In wintertime, lower demand for drinking water complements slower boiling times from PSCs due to colder outdoor temperatures in Anding district. The implication of seasonal drinking water consumption differences is that mass adoption of PSCs for yearround use is possible.

\section{Ease of Use}

The common user behavior of pouring boiling water into highefficiency insulated heat-retaining bottles after use of any water-boiling method increases the overall efficiency of energy savings from PSCs or other water boiling methods by storing the thermal energy of boiled water for many hours. In addition, retaining water heat through insulation overcomes the problem of the intermittent nature of solar energy [24], further making it possible to encourage mass adoption of PSCs for water purification through boiling.

\section{Multiple Fuel Use (Fuel Switching Behavior)}

Anding households' energy use for boiling fits the multiple fuel model of household energy use and does not support the energy ladder model in concordance with van der Kroon et al.'s findings (2013). Anding residents use coal and biomass (dirtier solid fuels) alongside solar and electricity (cleaner fuels) to purify water through boiling (Figure 4). Anding households use many technology-fuel combinations to boil water (Figure 8) including: cooking stoves that burn gaseous fuels (such as LPG, coal gas or biogas) or solid fuels (such as biomass or coal); heating stoves that burn solid fuels; electric appliances (such as tea kettles); and PSCs. Table 3 shows energy use data fits better within a multiple fuel model than the energy ladder model, suggesting that the surveyed Anding district households will take advantage of all fuels they can access. Even though 
data from this research does not fit the energy ladder model, the authors suggest a revision to the energy ladder model to include PSCs and other clean cooking technologies to more effectively describe household energy use as illustrated in Figure 2.

\section{Environmental and Human Health Benefits}

Burning solid fuels, such as biomass and coal, generates black carbon (BC) or soot, which degrades air quality, causing serious impacts to both human and environmental health [59]. The substitution of indoor solid fuel combustion with PSC use results in an immediate improvement of indoor air quality. However, the positive impacts of this substitution are not limited to the home and can lead to improved regional environmental impacts as well. Past research regarding south Asia has found that emissions from burning solid fuels in cookstoves are the main source of $\mathrm{BC}$, a likely underestimated component in accelerating climate change [60] over the Indian Ocean [61]. Thus, concern over demand-side clean energy use has led to an increase in the promotion of gaseous fuels and electricity.

However, although electricity used for boiling water in the home does not generate direct emissions within the home, power plant (supply-side) emissions negatively affect human health through poor regional air quality. In most of China, Gansu province included, electricity is largely generated at coal-fired power plants [62], which create fine particulate matter (PM2.5) correlated with increased incidence of hospitalizations and deaths from respiratory and cardiac disease [63]. Therefore, use of PSCs reduces the combustion of solid fuels at multiple points and thus avoids the negative effects on both human and environmental health inherent in their usage.

\section{Energy Cost Reductions}

Use of PSCs to boil water has economic benefits for households in Anding district. A statistically significant reduction in energy costs was found for households that used PSCs year-round as compared to households that did not own PSCs for boiling water (Table 4). Households that use PSCs all year spend less on energy, with an average of 484 $\mathrm{RMB} /$ person-year $(n=110)$. Households that do not have PSCs spend more on energy, with an average of $785 \mathrm{RMB} /$ person-year $(n=32)$. As suggested by the results of our cross-sectional analysis and shown in Figure 9, PSC use in Anding has the potential to reduce energy expenditure by an amount significant to annual household income. These potential savings are in part due to the fact that households that do not use PSCs purchase ten times more coal gas. This finding implies that using a PSC can substantially reduce household energy costs, which is important for lowincome regions like Anding district. 


\section{PSC Use in the Broader Context}

Parabolic solar cookers have not been easily adopted in many communities despite energy and human health gains [10]. The key to improving indoor air quality through clean cooking technology is not simply a matter of economic development as the energy ladder model suggests. Cultural barriers have significantly limited the use of solar cookers and must be addressed to facilitate more widespread adoption of this technology [29,30]. Energy poverty involves lack of options, including sustainable energy types [12]. The Anding district household energy survey findings support what other researchers have found in other locations, that as poor households gain access to new energy sources, sustainable or not, they still keep using the familiar energy sources in line with the multiple fuel model [36,37]. Rather, for households in Anding district, the inclusion of PSCs as part of a multifuel household energy portfolio resulted in more sustainable energy use choices, leading to energy expenditure savings (Table 4) and the potential for improved indoor air quality by reducing coal use per person-year (Figure 9). In addition, the majority of Anding district households surveyed owned and used PSCs for water purification by boiling, which is significant because of PSC adoption problems as a clean cooking technology in other regions [10].

Parabolic solar cookers are an ideal and appropriate technology for purification of drinking water in Anding district because of these factors:

- Cultural: the cultural norm is to drink boiled water hot.

- Climate: there is sufficient sunlight to boil water year-round.

- Environmental: PSCs create no pollutants, thereby preserving indoor and outdoor air quality.

- Geographical: houses and communities are spread far apart, making connected energy and water infrastructure expensive and challenging.

- Socio-technical: centralized water delivery and treatment does not exist.

- Ease of use: heat-insulating bottles are used to retain water heat.

- User behavior: fuel-switching behavior and multiple technology-fuel combinations are used within households to boil water, especially seasonally.

- Economic: PSCs reduce household energy expenditures when used year-round.

Parabolic solar cookers are well suited for water purification because water can be boiled while the sun is up and kept hot in insulated bottles for later use. The findings of this research demonstrate that PSCs can be used in the winter in a temperate climate for primary water-boiling purposes. In the winter, Anding households also possess alternative technology-fuel combinations for water treatment, specifically the secondary use of ambient heating stoves to boil water. If poor rural residents living with no running water can adopt PSCs, then this technology may work for other communities as well. Other communities 
that meet some of these criteria may also have success in adopting PSCs for water purification by boiling.

Household water treatment (HWT) practices vary around the world and include boiling, chemical treatment and filtration, although they are not always practiced in every home in LICs. In their exhaustive study on HWT, Rosa and Clasen (2010) report that although boiling is the most common HWT practice reported globally by households in low- and medium-income countries (21\%), it is much less common in Africa (4.5\%)[64]. However, in a country like Uganda, where boiling is reported to be practiced by $34.4 \%$ of the rural population (and $68.6 \%$ of urban homes) and where $72.7 \%$ of the population uses 'traditional' cookstoves to meet their water boiling and cooking needs, alternative technology such as PSCs have the potential for higher acceptance rates because of the cultural practice of boiling water [65].

Therefore, PSC promotors would be more effective if they consulted with resources that can inform them on the cultural acceptance of water boiling as effective HWT. Data from 2010 reveals that the regions with the comparatively highest rates of water boiling in rural areas are the Western Pacific (57.7\%) and Southeast Asia (including India, Nepal and Bangladesh$31.5 \%)(64)$. In terms of the potential economic, environmental and health impacts of PSCs on solid fuel use in traditional cookstoves for water boiling, Rosa and Clasen (2010) call for more country-specific research in order to understand household energy use for cooking versus for boiling as an HWT practice. However, studies have been conducted to understand this energy use differentiation in rural Vietnam [66] and semi-urban India [67].

\section{CONCLUSIONS}

Given that the UN has included access to both clean water and clean cooking options as elements of the SDGs, institutional policies that promote the integration of PSC water purification systems with water projects are recommended in areas where the factors for successful adoption exist. This household energy survey of rural Anding district, Gansu province, China showed that $58 \%$ of households surveyed use PSCs for water purification via boiling in summer (12\%) or year-round (46\%) (Figure 3). Analysis of the survey data showed that energy expenditures are lower in households using PSCs year-round to purify water by boiling.

\section{Rethinking Energy Use Models}

Energy use in Anding for water boiling demonstrated an and approach instead of an either/or approach to technology and fuel adoption. The and approach fits better with the multiple fuel model description of household energy use that has been observed in other LICs [36,37]. In order to persuade impoverished households to adopt new energy technologies, alternatives must remain available. The goal is not to convince low-income households to switch completely to clean technology-fuel combinations. Rather, it is to give them access to technology-fuel combinations that 
reduce their environmental and economic burden. By encouraging households to incorporate new technologies without requiring them to abandon the old and familiar, a transition to more sustainable choices and livelihoods can occur with less social resistance to change. The assumptions inherent in energy use models inform policy directions; the multiple fuel use model is the appropriate model to influence policy about adoption of clean cooking technology in LICs.

\section{Limitations and Future Directions}

This research was limited to PSC use to boil water at the household scale. For future work, community-scale water projects could feasibly include water purification with PSCs. Many decentralized water supply projects integrate chlorine dispensers at well sites. These projects can fail because chlorine is not replenished due to lack of interest [68], cost, lack of availability or even lack of capacity due to issues with development project handover to communities [69]. The design of a community water handpump project in countries such as Uganda and Zambia, where water boiling is more culturally accepted than in other countries in Africa [64], could incorporate a co-located PSC to allow for the immediate boiling of water on site. Parabolic solar cookers at well sites would require little to no maintenance or expense after the initial purchase and would fit well with clean water access goals. Integrating PSCs with water hand-pump projects at schools or other locations where people stay for several hours would allow for water purification to happen via boiling because several hours is enough time to boil water in a PSC on a sunny day in almost any season. Safety concerns include fires-either accidental or intentionaland injuries such as cuts and burns, among others [70]. Some of these concerns can be addressed by PSC design improvements, while others can be addressed by controlling access and training about PSC use.

Future household energy surveys in Anding district could ask questions regarding barriers to adoption of PSCs and other renewable and energy efficient technologies explicitly to better understand how to encourage mass adoption of PSCs and other clean cooking technologies. Further understanding of how biomass is utilized by poor rural residents is needed by taking samples of the energetic content of biomass utilized and weighing household usage to more accurately estimate the use of different types of biomass as a fuel. Finally, considering whether PSC adoption will be accepted and practiced by different communitiesthat meet some of the criteria identified above is needed to test the limits of mass adoption of PSCs for water purification by boiling and to identify which criteria are essential to as opposed to which criteria may only limit PSC adoption.

\section{Policy implications}

Past success of policies and incentives promoting biogas digester adoption in Gansu and other Chinese provinces suggests that government efforts can influence households to purchase and install renewable energy 
technologies [17]. Li et al. (2009)[44] compared energy types in terms of convenience, household energy cost, and environmental impact for Tongwei and Qin'an districts in Gansu; their findings suggest that promoting solar is a prudent policy approach. The documented success of PSC use for water treatment in Anding district suggests that PSC adoption is a potential environmental and economic win for energy-water nexus problems faced by impoverished rural residents around the world.

\section{DATA AVAILABILITY}

The dataset of the study is available from the authors upon reasonable request.

\section{AUTHOR CONTRIBUTIONS}

ACS and JQ designed the study and performed data collection. ACS, JQ, and CD analyzed the data. ACS and CD wrote the paper with substantial input from JQ.

\section{CONFLICTS OF INTEREST}

The authors declare that there is no conflict of interest.

\section{FUNDING}

This research was funded by the Chinese Academy of Sciences Fellowship for Young International Scientists and National Natural Science Foundation of China (NSFC) Research Fund for International Young Scientists and National Key Research and Development Program of China (No. 2016YFA0602803).

\section{ACKNOWLEDGMENTS}

Thanks to Alison Treglia for her help with statistical analysis. 


\section{APPENDICES}

Appendix A1. Number of Appliances bought with the Appliances to Countryside program.

\begin{tabular}{lcc}
\hline Appliance & $\begin{array}{c}\text { \# Appliances to Countryside } \\
\text { program purchases }\end{array}$ & Total \# appliances \\
\hline Computer & 0 & 23 \\
DVD/VCD & 0 & 149 \\
Electric blanket & 0 & 242 \\
Electric heater & 0 & 189 \\
Electric hot water heater & 0 & 0 \\
Electric Tea Kettle & 4 & 46 \\
Electric wok & 0 & 16 \\
Freezer & 4 & 18 \\
Hay conditioner/silage grass crushers & 0 & 79 \\
Induction hot plate & 3 & 116 \\
Landline telephone & 0 & 147 \\
Microwave & 0 & 9 \\
Radio & 0 & 45 \\
Refrigerator & 6 & 58 \\
Rice cooker & 0 & 162 \\
Satellite dish & 0 & 205 \\
Smasher/Grinder (agricultural use) & 0 & 2 \\
Solar hot water heater & 0 & 20 \\
Solar stove & 0 & 201 \\
Speakers & 0 & 116 \\
Toaster oven & 0 & 2 \\
TV & 1 & 275 \\
Washing Machine & 0 & 189 \\
Water cooler (water purifier) & 0 & 20 \\
Totals & $\mathbf{1 8}$ & $\mathbf{2 3 2 9}$ \\
\hline
\end{tabular}

Appendix A2. Contingency Analysis Table and Pearson's Chi squared statistic.

\begin{tabular}{|c|c|c|c|c|c|}
\hline & \multicolumn{5}{|c|}{ PSC Use } \\
\hline & Count & \multirow{3}{*}{ All Year } & \multirow{3}{*}{ None } & \multirow{3}{*}{ Summer } & \multirow{3}{*}{ Total } \\
\hline & Expected & & & & \\
\hline & Cell Chi^2 & & & & \\
\hline \multirow{13}{*}{ 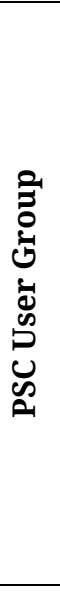 } & \multirow{3}{*}{ All Year PSC Use } & 110 & 0 & 0 & 110 \\
\hline & & 51.05 & 45.49 & 13.46 & \\
\hline & & 68.05 & 45.49 & 13.46 & \\
\hline & \multirow{3}{*}{ No PSC } & 0 & 66 & 0 & 66 \\
\hline & & 30.63 & 27.29 & 8.08 & \\
\hline & & 30.63 & 54.9 & 8.08 & \\
\hline & \multirow{3}{*}{ No PSC Use } & 0 & 32 & 0 & 32 \\
\hline & & 14.85 & 13.23 & 3.92 & \\
\hline & & 14.85 & 26.62 & 3.92 & \\
\hline & \multirow{3}{*}{ Summer Only } & 0 & 0 & 29 & 29 \\
\hline & & 13.46 & 11.99 & 3.55 & \\
\hline & & 13.46 & 11.99 & 182.55 & \\
\hline & Total & 110 & 98 & 29 & \\
\hline
\end{tabular}




\section{Appendix A3}

Anding district receives 3 kilowatt-hours $(\mathrm{kWh}) /$ meters squared per day of solar irradiation [71]. The PSC has 1.5 meters squared of area, thus the PSC receives $4.5 \mathrm{kWh}$ per day of solar irradiation in Anding district. $9.75 \mathrm{~h}$ of sunlight occur in Dingxi city, Anding district $\left(35.5807^{\circ} \mathrm{N}, 104.6263^{\circ}\right.$ E) during winter solstice, the day of minimum sunlight hours annually according to the National Oceanic and Atmospheric Administration (NOAA)[72]. There are $3600 \mathrm{~kJ}$ to every kWh. Thus, it takes $0.36 \mathrm{kWh}$ of effective sunlight energy received to boil a teapot of water. The PSC energy conversion efficiency rate comes from [25] at 26.6\%.

$$
\begin{gathered}
T_{W B}=\frac{N R G_{W B}}{N R G_{S} * \mathrm{PSC}_{e}}=\frac{0.36 \mathrm{kWh} / \text { teapot }}{0.46 \frac{\mathrm{kWh}}{\mathrm{hour}} * 26.6 \%}=3.00 \text { hours to boil water } / \text { teapot } \\
N_{W B}=\frac{T_{S}}{T_{W B}}=\frac{9.75 \text { hours sunlight daily }}{3.00 \text { hours/teapot }}=3.25 \text { teapots daily }=3 \text { teapots boiled water daily }
\end{gathered}
$$

Where

$T_{W B}=$ time to boil water in a teapot

$N R G_{W B}=$ energy needed to boil water in a teapot in $\mathrm{kWh}$

$N R G_{S}=$ average solar irradiation incident on PSC in $\mathrm{kWh} / \mathrm{h}$

$P S C_{e}=$ efficiency of conversion of incident solar irradiation into effective energy for boiling water in \%

$T_{S}=$ sunlight hours per day (minimum annually)

$T_{W B}=$ hours to boil water in a teapot

$N_{W B}=$ number teapots of water boiled daily from average solar irradiation and minimum sunlight hours

Appendix A4. Average PSC use by summer, winter, and annually by PSC user group.

\begin{tabular}{lccccc}
\hline PSC age & $\begin{array}{c}\text { All Year } \\
\mathbf{( 1 1 0 )}\end{array}$ & $\begin{array}{c}\text { Summer } \\
\text { Only (29) }\end{array}$ & $\begin{array}{c}\text { No PSC } \\
\text { Use (66) }\end{array}$ & $\begin{array}{c}\text { No PSC } \\
\text { (32) }\end{array}$ & $\begin{array}{c}\text { All Households } \\
\text { (237) }\end{array}$ \\
\hline Average & 6.40 & 6.88 & 7.25 & n/a & 6.74 \\
Minimum & 1 & 3 & 2 & n/a & 1 \\
Maximum & 15 & 10 & 15 & n/a & 15 \\
Median & 6 & 7 & 7 & & 6 \\
Mode & 5 & 10 & 10 & & 10 \\
Number of Households Responding & 107 & 26 & 64 & n/a & 197 \\
\hline
\end{tabular}

Two households responded that they did not know the age of the PSC they owned.

\section{REFERENCES}

1. United Nations. Clean water and sanitation: why it matters. 2017. Available from: https:/www.un.org/sustainabledevelopment/wp-content/uploads/2016/08/ 6_Why-it-Matters_Sanitation_2p.pdf. Accessed 2019 Aug 20.

2. Shrestha LG, Shrestha R, Spuhler D. Boiling. Sustainable Sanitation and Water Management. 2017. Available from: https://www.sswm.info/sswm-universitycourse/module-6-disaster-situations-planning-and-preparedness/furtherresources-0/boiling. Accessed 2018 Mar 13. 
3. World Bank. Unlocking Clean Cooking and Heating Solutions Key to Reaching Sustainable Energy Goals. 2015. Available from: http://www.worldbank.org/ en/news/feature/2015/05/19/unlocking-clean-cooking-and-heating-solutionskey-to-reaching-sustainable-energy-goals. Accessed 2018 Jun 7.

4. United Nations. Affordable and clean energy: why it matters. 2016. Available from: http:/www.un.org/sustainabledevelopment/wp-content/uploads/2016/ 08/7_Why-it-Matters_Goal-7_CleanEnergy_2p.pdf. Accessed 2017 Jun 23.

5. Behrens A, Lahn G, Dreblow E, Ferrer JN, Carraro M, Veit S. Escaping the vicious cycle of poverty: towards universal access to energy. Brussels (Belgium): European Parliament; 2012. Report No.: 363. Available from: https://www.ceps.eu/system/files/WD\%20363\%20\%20Behrens\%20et\%20al\%2 0Energy\%20in\%20Developing\%20Countries.pdf. Accessed 2017 Dec 2.

6. World Health Organization (WHO). Household air pollution and health. 2016. Available from: http:/www.who.int/mediacentre/factsheets/fs292/en/. Accessed 2017 Dec 6.

7. Wallack JS, Ramanathan V. The other climate changers: Why black carbon and ozone also matter. Foreign Aff. 2009;88(5):105-13.

8. Clancy J, Winther T, Matinga M, Oparaocha S. Gender equity in access to and benefits from modern energy and improved energy technologies: world development report background paper. Leusden (Netherlands): ETC/ENERGIA in association Nord/Sør-konsulentene; 2012. Available from: https://research.utwente.nl/en/publications/gender-equity-in-access-to-andbenefits-from-modern-energy-and-im. Accessed 2018 May 23.

9. Parikh J. Hardships and health impacts on women due to traditional cooking fuels: A case study of Himachal Pradesh, India. Energ Pol. 2011;39(12): 7587-94

10. Otte PP. Solar cookers in developing countries-What is their key to success? Energ Pol. 2013;63:375-81.

11. Smith KR. What's Cooking? A Brief Update. Energy Sustain Dev. 2010;14(4):251-2.

12. Bhide A, Monroy CR. Energy poverty: A special focus on energy poverty in India and renewable energy technologies. Renew Sustain Energy Rev. 2011;15(2):1057-66.

13. The Office of the Leading Group for Promoting the Sustainable Development Strategy, P.R.China (OLGPSDS). Review Sustainable Development in China (2008) - Agriculture, Rural Development, Land, Drought and Desertification. Beijing (China): Department of Regional Economy National Development and Reform Commission; 2008. Available from: http://www.un.org/esa/agenda21/ natlinfo/countr/china/2007_fullreport.pdf. Accessed 2017 Dec 11.

14. Tao T, Xin K. Public health: A sustainable plan for China's drinking water. Nature. 2014;511(7511):527-8.

15. Zhang JJ, Smith KR. Household Air Pollution from Coal and Biomass Fuels in China: Measurements, Health Impacts, and Interventions. Environ Health Perspect. 2007;115(6):848-55. 
16. Hao J, Zhu T, Fan X. Indoor Air Pollution and Its Control in China. In: Pluschke $\mathrm{P}$, Schleibinger H, editors. Indoor Air Pollution. 2nd ed. Berlin (Germany): Springer; 2014. p. 1-26. doi: 10.1007/698_2014_257

17. Wang X, Lu X, Yang G, Feng Y, Ren G, Han X. Development process and probable future transformations of rural biogas in China. Renew Sustain Energy Rev. 2016;55:703-12.

18. China Daily. Dingxi city. Gansu Province, China. 2013. Available from: http://www.chinadaily.com.cn/m/gansu/2013-10/17/content_17038888.htm. Accessed 2019 Jun 5.

19. Clarke-Sather A. State power and domestic water provision in semi-arid Northwest China: Towards an aleatory political ecology. Polit Geogr. 2017;58(Supplement C):93-103.

20. Lin Z. Small Potatoes Open a Wider World. China Today. 2015. Available from: http://www.chinatoday.com.cn/english/economy/2015-08/05/content_698681.htm. Accessed 2017 Nov 16.

21. Wei X. Xi urges stepped-up efforts to eradicate poverty by 2020 . China Daily. 2017 Feb 23; Available from: http://www.chinadaily.com.cn/china/201702/23/content_28310971.htm. Accessed 2017 Nov 16.

22. Xinhua. Xi Jinping calls for poverty alleviation. China Daily. 2013 Feb 5. Available from: http://www.chinadaily.com.cn/china/2013-02/05/content_ 16203871.htm. Accessed 2017 Nov 16.

23. Panwar N, Kaushik S, Kothari S. Experimental investigation of energy and exergy efficiencies of domestic size parabolic dish solar cooker. J Renew Sustain Energy. 2012;4(2):023111.

24. Prasanna UR, Umanand L. Modeling and design of a solar thermal system for hybrid cooking application. Appl Energy. 2011;88(5):1740-55.

25. Arenas JM. Design, development and testing of a portable parabolic solar kitchen. Renew Energy. 2007;32(2):257-66.

26. Chen X, Gao Y. Research and development of solar cookers in China. Bioenergy China. 1989;20(1):113-23.

27. Fang X, Li D. Solar photovoltaic and thermal technology and applications in China. Renew Sustain Energy Rev. 2013;23:330-40.

28. Roberts BJ. Solar Resource of China: Flat Plate Tilted at Latitude. Golden (US): National Renewable Energy Laboratory (NREL); 2012. Available from: https://www.nrel.gov/gis/images/international_solar/china_solar_pv-01.jpg. Accessed 2017 Nov 8.

29. Tucker M. Can solar cooking save the forests? Ecol Econ. 1999;31(1):77-89.

30. Kimambo CZM. Development and performance testing of solar cookers. J Energy South Afr. 2007;18(3):41-51.

31. Biermann E, Grupp M, Palmer R. Solar cooker acceptance in South Africa: results of a comparative field-test. Sol Energy. 1999;66(6):401-7.

32. Iessa L, De Vries YA, Swinkels CE, Smits M, Butijn CAA. What's cooking? Unverified assumptions, overlooking of local needs and pro-solution biases in the solar cooking literature. Energy Res Soc Sci. 2017;28:98-108.

33. Baptista TL, Curnow K, Hiranaga BJ, Magnus BD, Perry D. Solar Household Energy, Incorporated: A Market-Based Strategy for Introducing Passive Solar 
Ovens in Kenya. Ann Arbor (US): University of Michigan Business School; 2003. Available from: http://solarcooking.org/research/keyansolarovenmarket.pdf. Accessed 2018 Aug 13.

34. Otte PP. A (new) cultural turn toward solar cooking-Evidence from six case studies across India and Burkina Faso. Energy Res Soc Sci. 2014;2:49-58.

35. Hosier RH, Dowd J. Household fuel choice in Zimbabwe: an empirical test of the energy ladder hypothesis. Resour Energy. 1987;9(4):347-61.

36. Masera OR, Saatkamp BD, Kammen DM. From Linear Fuel Switching to Multiple Cooking Strategies: A Critique and Alternative to the Energy Ladder Model. World Dev. 2000;28(12):2083-103.

37. van der Kroon B, Brouwer R, van Beukering PJH. The energy ladder: Theoretical myth or empirical truth? Results from a meta-analysis. Renew Sustain Energy Rev. 2013;20:504-13.

38. Rehfuess E. Fuel for life: household energy and health. Geneva (Switzerland): World Health Organization (WHO); 2006. Available from: https://www.who.int/indoorair/publications/fuelforlife/en/. Accessed 2016 Dec 3.

39. Pew Research Center. World Population by Income. Pew Research Center (US): Pew Research Center. 2015. Available from: http://www.pewglobal.org/ interactives/global-population-by-income/. Accessed 2017 Nov 17.

40. Cashman S, Rodgers M, Huff M, Feraldi R, Morelli B. Life Cycle Assessment of Cookstove Fuels in India and China. Washington, D.C (US): EPA; 2016. Report No.: EPA/600/R-15/325. Available from: http://cleancookstoves.org/binarydata/RESOURCE/file/000/000/496-1.pdf. Accessed 2018 Jun 12.

41. Dressler D, Loewen A, Nelles M. Life cycle assessment of the supply and use of bioenergy: impact of regional factors on biogas production. Int J Life Cycle Assess. 2012;17(9):1104-15.

42. Bruun S, Jensen LS, Khanh Vu VT, Sommer S. Small-scale household biogas digesters: An option for global warming mitigation or a potential climate bomb? Renew Sustain Energy Rev. 2014;33:736-41.

43. Rajendran K, Aslanzadeh S, Taherzadeh MJ. Household Biogas Digesters-A Review. Energies. 2012;5(8):2911-42.

44. Li G, Niu S, Ma L, Zhang X. Assessment of environmental and economic costs of rural household energy consumption in Loess Hilly Region, Gansu Province, China. Renew Energy. 2009;34(6):1438-44.

45. Niu H, He Y, Desideri U, Zhang P, Qin H, Wang S. Rural household energy consumption and its implications for eco-environments in NW China: A case study. Renew Energy. 2014;65:137-45.

46. Tonooka Y, Liu J, Kondou Y, Ning Y, Fukasawa O. A survey on energy consumption in rural households in the fringes of Xian city. Energy Environ Resid Build China. 2006;38(11):1335-42.

47. Clarke-Sather A, Li Y, Qu J. Lighting energy use in Anding District, Gansu Province, China. Energy Sustain Dev. 2016;32:40-9.

48. McDonald JH. Chi-square test of independence. In: Handbook of Biological Statistics. 3rd ed. Baltimore (US): Sparky House Publishing; 2015. Available from: http://www.biostathandbook.com/chiind.html. Accessed 2017 Jul 19. 
49. Ross A, Willson VL. One-Way Anova. In: Ross A, Willson VL, editors. Basic and Advanced Statistical Tests: Writing Results Sections and Creating Tables and Figures. Rotterdam (Netherlands): SensePublishers; 2017. p. 21-4. doi: 10.1007/978-94-6351-086-8_5

50. Hilton A, Armstrong RA. Statnote 6: post-hoc ANOVA tests. In: Microbiologist. London (UK): Society for Applied Microbiology; 2006; p. 34-6.

51. Rosenthal L, Carroll-Scott A, Earnshaw VA, Santilli A, Ickovics JR. The importance of full-time work for urban adults' mental and physical health. Soc Sci Med. 2012;75(9):1692-6.

52. Xinhua. China '12 rural home appliance sales jump 18.8\%. China Daily. 2013 Aug 1. Available from: http://www.chinadaily.com.cn/business/201301/08/content_16094148.htm. Accessed 2019 Jul 10.

53. Ghasemi A, Zahediasl S. Normality tests for statistical analysis: a guide for non-statisticians. Int J Endocrinol Metab. 2012;10(2):486-9.

54. Davis CR. Homogeneity of Variance. In: Salkind NJ, editor. Encyclopedia of Research Design. Thousand Oaks (US): SAGE Reference; 2010. p. 577-80. Available from: http://link.galegroup.com/apps/doc/CX1959400188/GVRL?u= mnauduluth\&sid=GVRL\&xid=3faa724f. Accessed 2019 Jun 11.

55. MBH Media. Chinese Yuan Renminbi Exchange Rate-US Dollar-Historical Exchange Rates. 2019. Available from: https://www.exchangerates.org/history/CNY/USD/T. Accessed 2019 Jun 12.

56. Wang H. Small Potatoes, Big Industry. Beijing Review. 22nd ed. 2015 May 28. Available from: http://www.bjreview.com.cn/nation/txt/2015-05/25/content_ 689377.htm. Accessed 2018 May 23.

57. Hongxing L, Wei Y, Guoqing D, Li W, Qing L, Shan W, et al. Water and sanitation interventions to control diarrheal disease in rural China. J Water Sanit Hyg Dev. 2016;6(4):640-9.

58. Cohen A, Tao Y, Luo Q, Zhong G, Romm J, Colford JM, et al. Microbiological Evaluation of Household Drinking Water Treatment in Rural China Shows Benefits of Electric Kettles: A Cross-Sectional Study. PLoS One. 2015;10(9):e0138451.

59. Ezzati M, Kammen DM. Household energy, indoor air pollution, and health in developing countries: Knowledge base for effective interventions. Annu Rev Energy Environ. 2002;27:233-70.

60. Bond TC, Doherty SJ, Fahey D, Forster P, Berntsen T, DeAngelo B, et al. Bounding the role of black carbon in the climate system: A scientific assessment. J Geophys Res Atmospheres. 2013;118(11):5380-552.

61. Venkataraman C, Habib G, Eiguren-Fernandez A, Miguel AH, Friedlander SK. Residential biofuels in South Asia: Carbonaceous aerosol emissions and climate impacts. Science. 2005;307(5714):1454-6.

62. International Energy Agency (IEA). Renewables. 2017. Available from: https://www.iea.org/topics/renewables/. Accessed 2017 Jun 14.

63. Pope CA. Epidemiology of fine particulate air pollution and human health: biologic mechanisms and who's at risk? Environ Health Perspect. 2000;108(Suppl 4):713-23. 
64. Rosa G, Clasen T. Estimating the Scope of Household Water Treatment in Lowand Medium-Income Countries. Am J Trop Med Hyg. 2010;82(2):289-300.

65. Burleson G, Tilt B, Sharp K, MacCarty N. Reinventing boiling: A rapid ethnographic and engineering evaluation of a high-efficiency thermal water treatment technology in Uganda. Energy Res Soc Sci. 2019;52:68-77.

66. Clasen TF, Thao do H, Boisson S, Shipin O. Microbiological effectiveness and cost of boiling to disinfect drinking water in rural Vietnam. Environ Sci Technol. 2008;42(12):4255-60.

67. Clasen T, McLaughlin C, Nayaar N, Boisson S, Gupta R, Desai D, et al. Microbiological effectiveness and cost of disinfecting water by boiling in semi-urban India. Am J Trop Med Hyg. 2008;79(3):407-13.

68. Kestenbaum D. A Surprising Barrier To Clean Water: Human Nature. Planet Money. 2013. Available from: https://www.npr.org/sections/money/2013/06/ 20/193587906/a-surprising-barrier-to-clean-water-human-nature. Accessed 2017 Dec 5.

69. Clarke AR, Serrar M, Gershenson JK. A Sustainable Design Process Framework based on a Non-Profit Product Design Case Study. IV Global Conference on Sustainable Product Development and Life Cycle Engineering Sustainable Development; 2006 Oct 3-6; São Carlos, Brazil.

70. Edmonds I. Low cost realisation of a high temperature solar cooker. Renew Energy. 2018;121:94-101.

71. National Renewable Energy Laboratory (NREL). China Direct Normal Solar Irradiation. 2005. Available from: http://www.nrel.gov/gis/pdfs/swera/china/ china40kmdir.pdf. Accessed Dec 16, 2016.

72. National Oceanic and Atmospheric Administration (NOAA), Earth System Research Laboratory, Global Monitoring Division. NOAA Solar Calculator. NOAA Research. 2019. Available from: https://www.esrl.noaa.gov/ gmd/grad/solcalc/. Accessed 2019 Aug 20.

How to cite this article:

Clarke-Sather AR, Davis CJ, Qu J. Analysis of a Rural Northwestern China Household Energy Use Survey Focusing on Parabolic Solar Cooker Use for Water Purification. J Sustain Res. 2019;1:e190009. https://doi.org/10.20900/jsr20190009 